\title{
Student Performance in Online and Traditional Sections of an Undergraduate Management Course
}

\author{
Thomas Daymont and Gary Blau \\ Temple University
}

\begin{abstract}
Few previous studies comparing online and traditional courses have focused on undergraduate management courses. Our results complement previous analyses finding that, when we control for factors such as class, major, and GPA, students in online courses do as well in objective measures of performance, but not better than students in traditional courses. We also found that in the online sections, females performed at least as well as males. We discuss these results in relation to some changes in online education and the persistent perception by some that online education is somewhat problematic because students need more discipline in online courses.
\end{abstract}

\section{Introduction}

Various forms of distance education have existed for at least 100 years. For example, others have noted various types of correspondence programs during the 1800's at schools such as Illinois Wesleyan University, Pennsylvania State University, and the University of Chicago (Lemak, Shin, Reed \& Montgomery, 2005; Madden, 2003). As technology has changed, distance education has changed and grown. The continued growth suggests that the supply of distance and online courses and programs still lags the demand. In fact, survey results suggest that the growth in online courses continues unabated. For example, the results of a survey of active degree-granting institutions of higher education in the United States revealed that 1.6 million students took at least one online course in the Fall 2002 (Allen \& Seaman, 2006). Over the next three years, the annual percentage increase in the number of student taking at least one online course was 23 percent, 18 percent, and 35 percent. Thus, by the Fall 2005, 3.2 million students were taking at least one online course, about twice the number of only 3 years prior (Allen \& Seaman, 2006).

There appear to be several reasons why students seek online courses in increasing numbers. Some students may seek courses with a significant online component because they perceive that it is consistent with their preferred learning style or personality. Proserpio \& Gioia (2007) argue that web-based tools and courses may be more consistent than traditional approaches with the learning styles of a "virtual generation". Online courses, at least their asynchronous components, may be an advantage for those students who prefer written communications rather than oral, faceto-face interactions, or who desire more time to prepare their participation (Smith, 2001). Indeed, some studies have found evidence that students in online courses were more active participants than students in traditional courses (Shea, et al., 2002; Hiltz \& Shea, 2005). 
However, the primary advantage of online courses for students appears to be convenience (McEwen, 2001; Moskal \& Dziuban, 2001; Dutton, Dutton \& Perry, 2002; Bocchi, Eastman \& Swift, 2004; Hiltz \& Shea, 2005). For some students, inconvenience is such an overriding issue that it is actually a constraint. Because of work or travel schedule, or distance from campus, it may be impossible for some students to take a traditional classroom course. For others, it may be to some degree possible to take a traditional classroom course but more convenient to take an online course because of, for example, a changing or uncertain work schedule. For others, however, convenience may be an (unwitting?) euphemism for a desire for an easier or less demanding course. We worry that this may be the case when students say, for example, that they desire an online course because of their busy or demanding schedule of work, school, and or other activities, rather than because of a specific scheduling conflict. Of course, some students who choose traditional course formats also desire a less demanding course.

While online programs and courses are appealing to some students, they are sometimes met with a degree of skepticism by some administrators and employers (Madden, 2003; Bocchi, Eastman \& Swift, 2004). Part of the negative perception of online programs may be partly due to the fact that, historically, these programs tended to be operated by for-profit universities that are not as highly respected as traditional universities. In a Business Week survey of corporate recruiters, almost all said that they had not considered hiring an MBA with an online degree (Dash, 2000). This skepticism may be diminishing, however, as increasing numbers of prestigious universities are offering MBA and similar degrees with significant online components. Allen and Seaman (2006) found that among Chief Academic Officers of degree-granting institutions, 45 percent said that the learning outcomes of online education were the same as face-toface education. Seventeen percent said that they were at least somewhat superior, while 38 percent said that they were at least somewhat inferior. On the one hand, this means that the majority (62\%) believe that online education is the same or superior to traditional education. On the other hand, it means that more than twice as many Chief Academic Officers believe that online education is at least somewhat inferior as believe that it is at least somewhat superior. Yet, the survey also shows that the perception of the relative quality of online education is slowly improving. Institutions of higher education continue to evaluate the compatibility of online education with the school's mission (Madden, 2003).

\section{Student Performance in Online Courses}

While administrators and employers may still have a slightly negative perception of the quality of online education, the research on the quality of online or web-based education is more favorable. As part of their comprehensive review of the literature, Arbaugh \& Stelzer (2003) reviewed studies across disciplines and found that several studies have found no significant differences in student learning or course satisfaction, some have found significantly higher performance in web-based courses, and a few have found lower student performance. Similarly, in their review of asynchronous online courses (ALN's), Fjermestad, Hiltz \& Zhang (2005) found that of 47 measures of learning, 16 
showed ALN to be significantly better, 29 showed no significant difference, and 2 found face-to-face sections scoring higher.

The studies vary substantially in terms of the particular issue or course content being investigated. Some are comparing online programs with traditional programs, while others are studying online courses versus traditional courses or hybrid type courses. The course content varies substantially, with course containing technical content receiving perhaps more attention than non-technical fields. A variety of outcomes are examined, including student satisfaction, student's reported perceptions of learning, and student academic performance measured by varying degrees of objective versus subjective measures. The level of education under investigation ranges from high school, to undergraduate, to graduate and professional education. The setting ranges from degree programs to job training in industry.

Regarding online management education, most studies have focused on the MBA level rather than the undergraduate level (Arbaugh, 2000b; Friday, et. al. (2006). These studies of MBA students tended to find no differences or a slight advantage for online or more technology based education relative to more traditional education (Alavi, 1994; Alavi, Yoo \& Vogel, 1997; Ocker \& Yaverbaum, 1999). More recently, Arbaugh (2005b) found that, among MBA students taking online courses, the greater the perceived flexibility of the course, the greater the satisfaction with the course delivery medium as well as the greater perceived student learning. Arbaugh (2005b) put it his way, "This finding suggests that not only does the "anytime anywhere" flexibility of the online course format enhance student attitudes about the delivery medium, but that it may also enhance their learning".

While the majority of research on web-based or online management courses has been done with graduate programs, the majority of teaching with web-based courses has been at the undergraduate level. In one recent study focusing undergraduate management courses, Friday, et al., (2006) found no statistically significant differences between the online and traditional sections in terms of student performance as measured by their final grade in the courses. Their dependent variable, final course grade, appears to have been a function of a combination of relatively objective and subjective measures of performance. One of our dependent variables is final course grade which is also a combination of objective and subjective measures of performance. Thus, we hypothesize:

Hypothesis 1A: Controlling for measures of student's academic ability, the final course grade of students in online sections will not be different than the final course grade of students in traditional sections.

As described below, we also analyze a second measure of performance that is more objective than final grade. This measure is the student's average score on quizzes that were the same for online and traditional sections. We hypothesize: 
Hypothesis 1B: Controlling for measures of student's academic ability, the average quiz score for students in online sections will not be different than the average quiz score of students in traditional sections.

\section{Gender Differences Relating to Online Courses}

Previous research has found interesting gender differences that may influence the degree to which men and women choose and perform in online courses. In their extensive review of the literature of learning and teaching management on the web, Arbaugh \& Stelzer (2003) observed that although earlier studies tended to find less computer usage and higher computer anxiety among women, more recent studies show a reduction or elimination of this gender gap. They also found some gender differences in communication styles. For example, women have tended to seek to build more of a sense of community online, while men tended to provide longer, more fact based messages (Barrett \& Lally 1999).

Two more recent studies have found seemingly conflicting results regarding gender differences in performance in online business courses. In a study of satisfaction and perceived learning in about 50 online MBA courses, Arbaugh (2005b) concluded that, controlling for a number of factors, females had somewhat lower perceived learning than men. In contrast, in a study of undergraduate courses, Friday, et al. (2006) found that, controlling for professor experience, females earned higher final grades in online undergraduate "organization and management" and "strategic management" courses. Females also earned higher grades in the traditional "organization and management" courses, but not in the traditional "strategic management" courses. Of course, there are several differences in the two studies that may help explain the differences in results. Arbaugh (2005b) studied MBA courses, while Friday, et al. (2006) studied undergraduate management courses. Arbaugh (2005b) assessed perceived learning while Friday, et al. (2006) examined final course grades. The two studies also differed in the control variables included in the model. In their review, Arbaugh \& Stelzer (2003) argued that the significance of gender for web-based education is surely in a state of flux. It appears that the more recent research has yet to provide definitive answers. We hypothesize:

Hypothesis 2A: In the online sections, controlling for measures of student's academic ability, the final course grade for females will not be different than the final course grade for males.

Hypothesis 2B: In the online sections, controlling for measures of student's academic ability, the average quiz score for females will not be different than the average quiz score for males. 


\section{Methods}

Description of the Online and Traditional Sections of the Organization and Management

\section{Course}

The sample for the study includes all students in seven sections of an undergraduate Organization and Management course taken in either the Fall 2006 or Spring 2007 semesters in a large public university in a large eastern metropolitan area. This course is part of the core business curriculum and is required by all business majors and business minors, and is also taken by other students outside of the business school. Two of these sections were asynchronous online sections, one each in the Fall 2006 and Spring 2007 semesters. The other five were all conducted in the same, primarily traditional, format with some web-based components. Students self-selected through the registration process into either the traditional or online sections.

In the traditional sections, the majority of the in-class discussions reviewed, explained, or elaborated on the material in the textbook. Other class-time involved learning activities or discussion of other management related issues. Students in the traditional sections could earn credit toward their final grade based on the quantity and quality of their class participation. There were no required face-to-face classes or meetings in the online sections. Online students were invited to drop in on any traditional class meeting that they would like. To the best of our knowledge, none did.

\section{Measures of Dependent Variables: Final Course Grade and Average Quiz Score}

The first measure of student performance was the student's final grade for the course (coded $A=4.0, A-=3.7, B+=3.3, B=3.0, \ldots, F=0.0$ ). Final grades for the course were determined primarily by two measures, quizzes and forum discussions, in both the online and traditional sections. In the traditional sections, class participation also had a small influence on the final grade. The students' average score on 11 quizzes taken through the Blackboard platform comprised approximately 50 percent of their course grade in all sections. The quizzes were open-book and contained, on average, 30 multiple-choice questions, most of them drawn randomly from question pools. About 10 percent of the questions on each quiz were the same for all students. The question pools were the same for all sections. Each quiz was available to be taken by the student for approximately 2 weeks.

The second major component of the final grade in both the traditional and online sections was based on the forum discussions in the Discussion Board in the Blackboard platform. Several threads were initiated by the instructor in each of about 10 forums. Some of the threads asked for analyses of scenarios or situations drawn from the textbook or other sources. Other threads asked for comments or analyses of articles drawn from business publications, web-sites, videos, etc. Students were not required to respond to specific threads, nor a specific number of threads. They were asked to reply to those threads which interested them the most or for which they had the most to contribute. Their forum grade was determined by a combination of the quantity and the 
instructor's subjective evaluation of the quality of their contributions. Part of the guidance about quality involved the following suggestion: "Suppose you are a junior manager and your manager had asked you about the issue raised in the forum thread. Reply in a way that would impress your manager and/or provide her with useful information regarding the issue." Because online students did not attend any classes, it was expected that they would participate more in the forum discussions. The standard for achieving a specific forum grade (say, a B) in terms of the combination of the quantity and quality of the student's contribution was approximately twice as high in the online sections as in the traditional sections. Students who withdrew from the course before the deadline (grade $=\mathrm{W}$ ) were not analyzed on the final grade measure.

Of course, final grade is a combination of objective and subjective measures of performance. In order to use a more purely objective measure of student performance, we also analyzed average quiz score which was described above. Because of an error in constructing one of the quizzes in the Fall semester that made the quiz different across sections, only the results for 10 quizzes in the Fall semester were usable. Quiz score was measured as the percent of correct answers. Roughly, a score in the 90's was equivalent to an A, 80's a B, etc. Thus, a 10 point difference in average quiz score was approximately equal to one letter grade difference.

Some students did not take all the quizzes, thus we need to consider the treatment of a missing quiz score. It seems to us that most missing data on quiz score reflects one of two situations. First, the student was still engaged in the course, but due to a lack of time, effort, or knowledge, did not complete the quiz. Second, the student was no longer engaged in the course. Due to the absence of direct information on the reason for a missing quiz score, we used the following algorithm. If the student completed a subsequent quiz, we assumed that the student was still engaged in the course and assigned a quiz score of 25 based on the fact that the multiple-choice question contained 4 or 5 choices, and, thus, an unknowledgeable student could attain a score of approximately 20-25 percent by guessing. This is the same assumption that was made in calculating the student's course grade. If a student did not take any subsequent quizzes, then we assumed that the student was no longer engaged in the course at the time of the quiz, and the missing quiz score was ignored in calculating the average quiz grade for the student.

\section{Measures of Independent and Control Variables}

The first independent variable of interest is whether the student was in an online section $(=1)$, or a traditional section $(=0)$. The other independent variable of interest was gender (female), coded as female $=1$, male $=0$.

Several control variables were included. Class was a series of binary variables indicating the student's year in school (e.g., freshman, sophomore, etc.). Major was a series of binary variables indicating the student's major area of concentration if in the business school, or the school or college within the university if outside the business school. GPA was the student's cumulative grade point average. The cumulative GPA 
included the semester in which the organization and management course was taken. However, we used an estimate of the student's semester hours to recalculate cumulative GPA excluding the grade in the organization and management course. Semester was coded as Spring $2007=1$, Fall $2006=0$.

\section{Analytical Model}

The analysis was conducted using a series of regression analyses. For the analysis of average quiz score, we included students who took as few as 1 quiz. We suspect that average quiz score will be a more accurate indicator of the student's course knowledge for students who took more quizzes. Thus, we assumed that the size of the error variance would be inversely related to the number of quizzes taken. An analysis of the residuals supported this assumption. Thus, a weighted least squares analysis was used for average quiz score. When we ran the analysis including only students who took at least 8 quizzes, we obtained results very similar to the results reported below. We include a linear and squared term for GPA to allow for non-linear effects of GPA on the two measures of student performance.

\section{Results}

\section{Descriptive Comparisons of Online and Traditional Students}

Table 1 compares measured characteristics of the students in the online and traditional sections. The average final grade for the online students was 2.76 , which corresponds to a B-. The average final grade for students in the traditional sections was 2.51 , which is half-way between a C+ and a B-. This difference in final grade was not statistically significant. Online and traditional students did not differ significantly in their tendency to withdraw sufficiently early in the semester such that a final grade was not assigned. However, the difference in the more objective measure, average quiz score, was statistically significant at the .05 level. The average quiz score for the online students was 80.4 , which corresponds to a low B-. The average quiz score for students in the traditional sections was 77.45 , which correspond to a low $\mathrm{C}+$.

Students in the online section were more likely to be female, $59 \%$ versus $39 \%$ for the traditional sections. They also had higher cumulative GPA's, 2.96 versus 2.73 for students in the traditional sections. Students in the online section were also further along in their academic careers: $73 \%$ were juniors or seniors versus $47 \%$ for the traditional sections. There were significant differences in major. Perhaps most notably, students in the online sections were more likely to be non-business majors, $58 \%$ versus $22 \%$ for students in the traditional sections. In addition, online students were less likely to be transfer students, $45 \%$ versus $72 \%$ for traditional students. 
Table 1: Characteristics of Online and Traditional Students

Online

No. of students

Final Grade

Quiz average

Withdrew before grade

No. of quizzes

Female

Cumulative GPA

Spring semester

Transfer student

Class

Non-matriculated

Freshman

Sophomore

Junior

Senior

Major

Accounting

Actuarial Science

Business Law

Business Undecided

Finance

Human Resource Mgmt.

International Business

Mgmt Information Systems

Marketing

Risk Management

Business Other

Communications \& Theater

Education

Liberal Arts

Science \& Technology

Tourism and Hospitality

Mgmt.

University Studies

Other non-Business
64

2.76

80.39

$9 \%$

9.55

$59 \%$

2.96

$52 \%$

$45 \%$

$0 \%$

$2 \%$

$25 \%$

$39 \%$

$34 \%$

$6 \%$

$2 \%$

$5 \%$

$2 \%$

$11 \%$

$0 \%$

$3 \%$

$6 \%$

$8 \%$

$0 \%$

$0 \%$

$19 \%$

$3 \%$

$12 \%$

$5 \%$

$14 \%$

$2 \%$

$3 \%$
181

Traditional

2.51

77.45

$7 \%$

9.73

$39 \%$

2.73

$40 \%$

$72 \%$

$4 \%$

$9 \%$

$39 \%$

$36 \%$

$11 \%$

$18 \%$

$3 \%$

$2 \%$

$10 \%$

$10 \%$

$5 \%$

$7 \%$

$2 \%$

$14 \%$

$2 \%$

$6 \%$

$4 \%$

$3 \%$

$4 \%$

$3 \%$

$2 \%$

$2 \%$

$4 \%$

${ }^{\wedge} p<.1 .{ }^{*} p<.05 .{ }^{* *} p<.01 .{ }^{* *} p<.001$. 
$\underline{\text { Tests of Hypotheses 1A and 1B: Student Performance in Online versus Traditional }}$

\section{Sections}

The regression results for final grade are shown in Table 2A. The first model shows the same result as shown in the comparisons between online and traditional students in Table 1: the final grade for online students was about one-quarter of a letter grade higher than for traditional students. However, the results were not statistically significant and the $95 \%$ confidence interval of the coefficient would include zero. Thus, we cannot rule out the possibility that this difference is due to random factors rather than reflecting an underlying difference in performance between online and traditional students. Of course, the confidence interval also includes 0.5 . Thus, we cannot rule out the possibility that there is an underlying difference in performance between online and traditional students of one-half letter grade favoring online students.

As we add various control variables in models 2 thru 5 , the coefficient for online section remains statistically insignificant. The online coefficient is reduced when class and, then, GPA are added to the model.

This pattern of regression results is consistent with the notion that any advantage in terms of final grade for online students in this sample is because the online students were more likely to be juniors and/or seniors, and, especially, because the online students tended to have higher cumulative GPA's. The results from model 5 indicate that cumulative GPA is the one significant and strong predictor of the final grade in our Organization and Management course. Taken together, the results suggest that any apparent effects of other factors such as class (e.g., being a junior) are explained by the relationship between that factor and GPA (e.g., the fact that juniors have higher GPA's and GPA predicts final grade in our Organization and Management class).

The first regression model for of average quiz score (Table 2B) repeats the results from Table 1 showing that, on average, online students performed about one-quarter of a letter grade higher than traditional students on the same quizzes. This difference is statistically significant at the .05 level. As we add various control variables in models 2 thru 5 , the coefficient for online section is reduced and becomes statistically insignificant when class is added to the model. The size of the online coefficient is further reduced when GPA is added to the model. This is consistent with the notion that the higher performance of online students on the quizzes is because online students were more likely to be juniors and/or seniors, and tended to have higher cumulative GPA's.

Thus, both Hypotheses $1 \mathrm{~A}$ and 1B are supported in that, controlling for measures of student academic ability, there is no statistically significant difference between students in the online and traditional sections in (1) final course grade, nor (2) the more objective measure of average quiz score. More generally, these results support and complement previous analyses finding that, when we control for relevant factors, students in online courses, do as well but not better than students in traditional courses. 
Table 2A

Effects of Online Section and Other Factors on Final Grade

(Unstandardized Regression Coefficients)

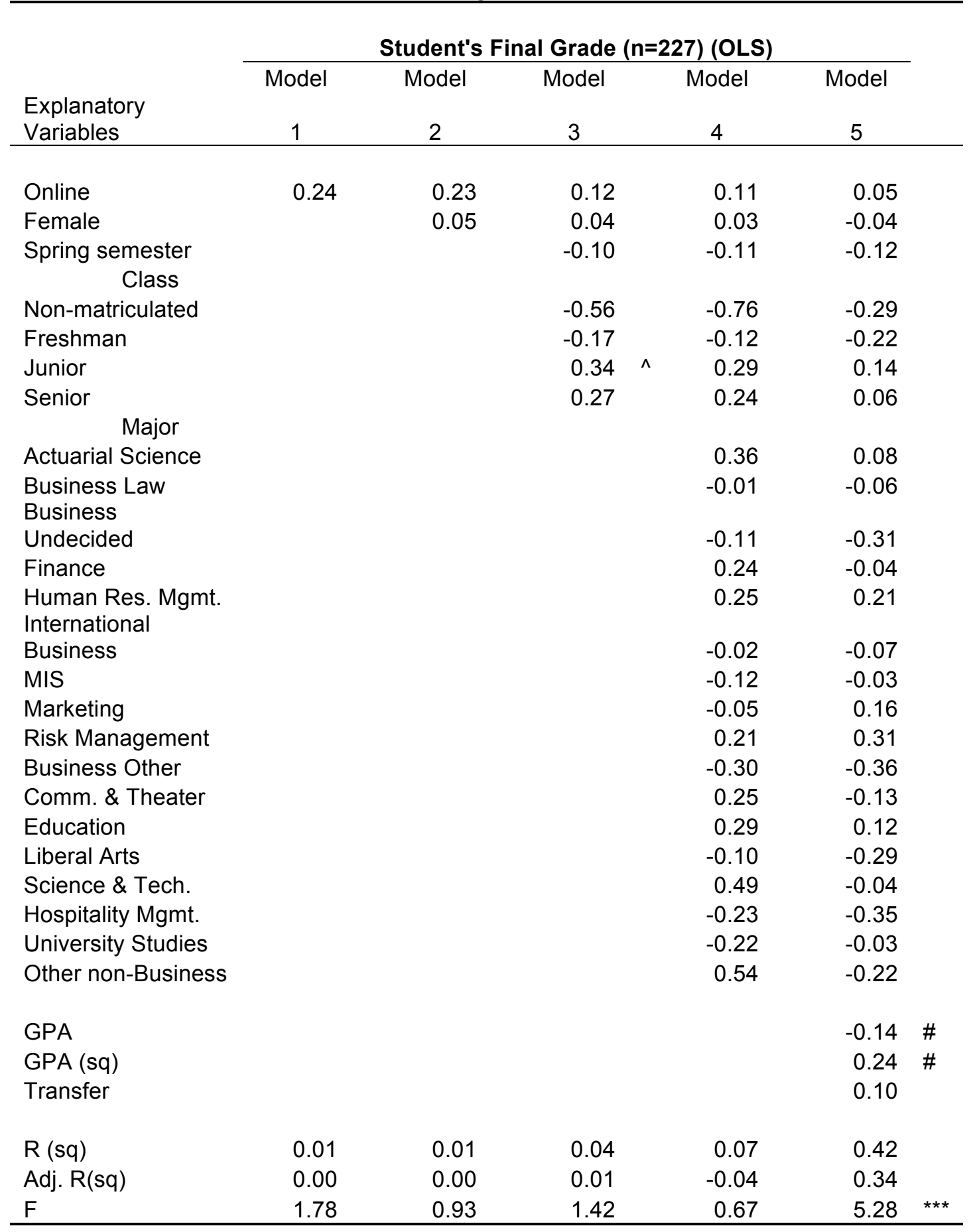

Note: Sophomore is omitted class category and Accounting is omitted Major category.

${ }^{\wedge} p<.1 .{ }^{*} p<.05 .{ }^{* *} p<.01 .{ }^{* * *} p<.001$.

\# The high statistical significance of GPA as an explanatory factor is not reflected

in the $p$ values because of the high colinearity of GPA and GPA squared. 
Table 2B

Effects of Online Section and Other Factors on Quiz Scores (Unstandardized Regression Coefficients)

\begin{tabular}{|c|c|c|c|c|c|c|c|c|c|c|}
\hline \multirow{3}{*}{$\begin{array}{l}\text { Explanatory } \\
\text { Variables }\end{array}$} & \multicolumn{9}{|c|}{ Average Quiz Score $(n=241)$ (WLS) } & \\
\hline & Model & & Model & & Model & & Model & & Model & \\
\hline & 1 & & 2 & & 3 & & 4 & & 5 & \\
\hline Online & 2.84 & * & 2.59 & * & 1.88 & & 1.79 & & 1.18 & \\
\hline Female & & & 1.05 & & 0.88 & & 0.73 & & 0.18 & \\
\hline Spring semester & & & & & 0.58 & & 0.54 & & 0.60 & \\
\hline Class & & & & & & & & & & \\
\hline Non-matriculated & & & & & -1.85 & & -3.16 & & -1.13 & \\
\hline Freshman & & & & & 1.37 & & 1.54 & & 0.47 & \\
\hline Junior & & & & & 3.19 & * & 3.53 & ** & 2.83 & * \\
\hline Senior & & & & & 2.12 & & 2.27 & & 1.52 & \\
\hline Major & & & & & & & & & & \\
\hline Actuarial Science & & & & & & & 4.92 & & 3.38 & \\
\hline Business Law & & & & & & & 5.13 & & 5.04 & \\
\hline Business & & & & & & & & & & \\
\hline Undecided & & & & & & & 1.83 & & 0.63 & \\
\hline Finance & & & & & & & 0.86 & & -0.54 & \\
\hline $\begin{array}{l}\text { Human Res. Mgmt. } \\
\text { International }\end{array}$ & & & & & & & 0.34 & & -0.69 & \\
\hline Business & & & & & & & 2.39 & & 1.51 & \\
\hline MIS & & & & & & & -0.67 & & 0.35 & \\
\hline Marketing & & & & & & & 1.86 & & 3.26 & $\wedge$ \\
\hline Risk Management & & & & & & & -0.12 & & 0.91 & \\
\hline Business Other & & & & & & & -2.47 & & -3.23 & \\
\hline Comm. \& Theater & & & & & & & 1.13 & & -2.31 & \\
\hline Education & & & & & & & 2.10 & & 0.89 & \\
\hline Liberal Arts & & & & & & & 0.71 & & -1.82 & \\
\hline Science \& Tech. & & & & & & & 3.55 & & -1.12 & \\
\hline Hospitality Mgmt. & & & & & & & -0.98 & & -2.29 & \\
\hline University Studies & & & & & & & 1.27 & & 1.93 & \\
\hline Other non-Business & & & & & & & 3.07 & & -2.18 & \\
\hline GPA & & & & & & & & & -7.91 & \# \\
\hline GPA (sq) & & & & & & & & & 2.91 & \# \\
\hline Transfer & & & & & & & & & -0.77 & \\
\hline $\mathrm{R}(\mathrm{sq})$ & 0.02 & & 0.03 & & 0.06 & & 0.10 & & 0.42 & \\
\hline Adj. R(sq) & 0.02 & & 0.02 & & 0.03 & & 0.00 & & 0.34 & \\
\hline $\mathrm{F}$ & 5.62 & * & 3.28 & * & 2.14 & * & 0.95 & & 5.67 & *** \\
\hline
\end{tabular}

Note: Sophomore is omitted class category and Accounting is omitted Major category.

${ }^{\wedge} p<.1 .{ }^{*} p<.05 .{ }^{* *} p<.01 .{ }^{* * *} p<.001$.

\# The high statistical significance of GPA as an explanatory factor is not reflected in the $p$ values because of the high colinearity of GPA and GPA squared. 
Tests of Hypotheses 2A and 2B: Results for Gender and Performance in Online $\underline{\text { Courses }}$

For both of the dependent variables, a series of models were run. The first model measures the "zero-order" or baseline gender difference in the measure of student performance (Tables $3 \mathrm{~A}$ and $3 \mathrm{~B}$ ). On average, females earned a final grade of one-half letter grade higher than males in the online sections (Table 3A). However, this difference is not statistically significant. As the control variables are added to the model, the effect of gender on final grade remains statistically insignificant and is reduced when cumulative GPA is added. Thus, Hypothesis $2 \mathrm{~A}$ is supported in that, controlling for measures of student academic ability, there is no statistically significant difference between students in the online and traditional sections in final course grade.

The results for the online sections in Table 3B show that, on average, females scored about one-third of a letter grade higher than males on the quizzes. However, this difference is not quite statistically significant at the traditional .05 level. When all of the control variables for class, major, GPA, etc. are added to the model, the effect of gender on average quiz score remains at about one-third of a letter grade, and not quite statistically significant at the .05 level. Thus, Hypothesis $2 \mathrm{~A}$ is supported in that, controlling for measures of student academic ability, there is no statistically significant gender difference in average quiz score in the online sections. However, it is not entirely clear whether our finding of an insignificant gender difference in our objective measure of student performance is because there is no gender difference or because our rather modest sample size limited our power in detecting a real female advantage.

These gender results are quite similar to those of Friday, et al. (2006) who also studied undergraduate management courses. The advantage of females over males in terms of final grade in online sections was somewhat smaller in their analysis, less than a third of a letter grade. However, their sample was larger, and the gender effect was statistically significant.

\section{Discussion}

Our study adds to our knowledge about the relative performance of online and traditional students in an under-investigated area: undergraduate management courses. Our results are similar to the results of Friday et al., the most recent previous study in this area, in that we found that, controlling for measures of student academic ability, online students performed as well but not better than traditional students. Also, females performed at least as well as males in the online course. Relative to earlier research in this area, our study was able to control for a richer array of measures of student academic ability and to examine a more objective measure of student performance. 
Table 3A

Effects of Gender and Other Factors on Final Grade

In Online Sections

(Unstandardized Regression Coefficients)

\begin{tabular}{|c|c|c|c|c|c|}
\hline \multirow{3}{*}{$\begin{array}{l}\text { Explanatory } \\
\text { Variables }\end{array}$} & \multicolumn{4}{|c|}{ Final Grade $(n=58)$ (OLS) } & \\
\hline & Model & Model & Model & Model & \\
\hline & 1 & 2 & 3 & 4 & \\
\hline Female & 0.50 & 0.40 & 0.65 & 0.30 & \\
\hline $\begin{array}{c}\text { Spring semester } \\
\text { Class }\end{array}$ & & 0.01 & -0.29 & -0.48 & \\
\hline Freshman & & $\mathrm{n} / \mathrm{a}$ & $\mathrm{n} / \mathrm{a}$ & $\mathrm{n} / \mathrm{a}$ & \\
\hline Junior & & 0.39 & 0.22 & 0.38 & \\
\hline Senior & & 0.43 & 0.45 & 0.20 & \\
\hline Major & & & & & \\
\hline Actuarial Science & & & 0.92 & 0.76 & \\
\hline Business Law & & & -1.47 & -1.04 & \\
\hline Finance & & & -0.57 & -0.15 & \\
\hline Int'l. Business & & & -1.80 & -0.80 & \\
\hline MIS & & & -0.89 & -1.08 & \\
\hline Marketing & & & -1.12 & -0.03 & \\
\hline Comm. \& Theater & & & -0.55 & -0.65 & \\
\hline Education & & & 0.86 & 0.11 & \\
\hline Liberal Arts & & & -0.89 & -0.72 & \\
\hline Science \& Tech & & & -0.63 & 0.43 & \\
\hline Hospitality Mgmt. & & & -0.58 & -0.64 & \\
\hline University Studies & & & 0.45 & 1.92 & \\
\hline Other non-Business & & & 0.25 & -0.29 & \\
\hline GPA & & & & 5.17 & \# \\
\hline GPA (sq) & & & & -0.61 & \# \\
\hline Transfer & & & & 0.49 & \\
\hline $\mathrm{R}(\mathrm{sq})$ & 0.04 & 0.06 & 0.22 & 0.64 & \\
\hline Adj. R(sq) & 0.02 & -0.01 & -0.12 & 0.44 & \\
\hline $\mathrm{F}$ & 2.41 & 0.89 & 0.65 & 3.23 & $* * *$ \\
\hline
\end{tabular}

Note: Sophomore is omitted class category and Accounting is omitted Major category.

${ }^{\wedge} p<.1 .{ }^{*} p<.05 .{ }^{* *} p<.01 .{ }^{* * *} p<.001$.

\# The high statistical significance of GPA as an explanatory factor is not reflected

in the $p$ values because of the high colinearity of GPA and GPA squared. 


\section{Table 3B}

\section{Effects of Gender and Other Factors on Quiz Scores in Online Sections (Unstandardized Regression Coefficients)}

\begin{tabular}{|c|c|c|c|c|c|c|c|c|}
\hline \multirow{3}{*}{$\begin{array}{l}\text { Explanatory } \\
\text { Variables }\end{array}$} & \multicolumn{7}{|c|}{ Average Quiz Score ( $n=62)$ (WLS) } & \\
\hline & Model & & Model & & Model & & Model & \\
\hline & 1 & & 2 & & 3 & & 4 & \\
\hline Female & 3.88 & $\wedge$ & 2.72 & & 4.85 & $\wedge$ & 3.21 & $\wedge$ \\
\hline $\begin{array}{c}\text { Spring semester } \\
\text { Class }\end{array}$ & & & 0.39 & & -1.03 & & -0.87 & \\
\hline Freshman & & & 4.24 & & 12.95 & & 6.48 & \\
\hline Junior & & & 4.06 & & 6.73 & $\wedge$ & 3.82 & \\
\hline Senior & & & 5.16 & $\wedge$ & 8.83 & * & 4.38 & \\
\hline Major & & & & & & & & \\
\hline Actuarial Science & & & & & 9.90 & & 8.87 & \\
\hline Business Law & & & & & -2.58 & & -0.40 & \\
\hline Finance & & & & & -0.24 & & 3.60 & \\
\hline Int'l Business & & & & & -7.68 & & -2.42 & \\
\hline MIS & & & & & -0.16 & & -1.78 & \\
\hline Marketing & & & & & 3.65 & & 5.41 & \\
\hline Comm. \& Theater & & & & & -2.05 & & -3.94 & \\
\hline Education & & & & & 6.75 & & -1.39 & \\
\hline Liberal Arts & & & & & -8.45 & & -8.11 & $\wedge$ \\
\hline Science \& Tech. & & & & & -3.20 & & -3.23 & \\
\hline Hospitality Mgmt. & & & & & -4.54 & & -5.25 & \\
\hline University Studies & & & & & 8.10 & & 17.24 & * \\
\hline Other non-Business & & & & & -4.62 & & -8.92 & $\wedge$ \\
\hline GPA & & & & & & & 47.85 & \# \\
\hline GPA (sq) & & & & & & & -5.78 & \# \\
\hline Transfer & & & & & & & 2.87 & \\
\hline $\mathrm{R}(\mathrm{sq})$ & 0.05 & & 0.10 & & 0.28 & & 0.72 & \\
\hline Adj. R(sq) & 0.03 & & 0.02 & & -0.02 & & 0.57 & \\
\hline $\mathrm{F}$ & 3.12 & * & 1.30 & & 0.94 & & 4.83 & $* * *$ \\
\hline
\end{tabular}

Note: Sophomore is omitted class category and Accounting is omitted Major category. ${ }^{\wedge} p<.1 .{ }^{*} p<.05 .{ }^{* *} p<.01 .{ }^{* *} p<.001$.

\# The high statistical significance of GPA as an explanatory factor is not reflected in the $p$ values because of the high colinearity of GPA and GPA squared. 
Our results for gender appear to be at least somewhat at odds with those of Arbaugh (2005b). He concluded that, controlling for a number of factors, females had somewhat lower perceived learning than men. However, there are several differences in the studies that may help explain the differences in results. As noted above, his sample consisted of MBA students while we studied undergraduates. He examined perceived learning while we studied average quiz score and final course grade. Also, his study covered courses conducted between 1998 and 2001, while ours covered courses conducted during the Fall 2006 and Spring 2007. While a difference of 6-8 years may not seem great, computer and internet technology, as well as online education has been changing rapidly. Some of the factors that had previously been identified as disadvantages for females in online education may have diminished or been eliminated.

As noted above, Arbaugh \& Stelzer's (2003) review of the literature revealed that although earlier studies tended to find that women used computers less and were more anxious about computer usage than men, more recent studies show a reduction or elimination of this gender gap. In addition, the technology used in many online courses has become, and is likely to continue to become, more user friendly (Goldman \& Hiltz, 2005). Certainly, the technical requirements for the online sections that serve as the basis for this study were minimal. The results of our study, as well as those of Friday, et al.(2006), reinforce the notion that to the extent that women were once at a disadvantage in online courses, it appears that they are not any more.

As discussed above, while attitudes towards online education appear to be becoming more favorable, it is still the case that a sizable proportion of educators, employers, and the public view online education as in some way inferior to traditional education. While the reasons for this somewhat negative perception of online learning may be many faceted, a recent survey of chief academic officers of institutions of higher education appears to have identified a primary reason. The chief academic officers were asked to agree or disagree about whether each of six factors was a barrier to the widespread adoption of online learning. One barrier was agreed with more than twice as much as any other potential barrier. Specifically, 64 percent of the respondents agreed with the statement that "students need more discipline to succeed in online courses" was a barrier to the widespread adoption of online learning (Allen \& Seaman, 2006). It certainly seems reasonable to believe that a lack of self-discipline would have a more severe impact on student performance in, especially asynchronous, online courses where students are often attracted by the appeal of anytime, anywhere structure of the course. Now, to the extent that this is true, and is an important factor, then we would expect that it would have a negative influence on the success of students in online courses. Moreover, it would seem to be at least somewhat inconsistent with our finding, and the finding of other studies, that online students and traditional students performed equally well.

To reconcile this inconsistency, we should perhaps consider possible compensating factors that may counterbalance the potential greater negative effect of the lack of selfdiscipline in online courses. One potential factor is differences in academic ability between online and traditional students. However, we found that online and traditional 
students performed equally well controlling for several measures of student ability (e.g., cumulative GPA. class, and major). Another potential factor is the possibility that instructors of online courses somehow have lower standards in online courses. This would reveal itself if, for example, the relative performance of online students was lower on more objective measures of performance than on more subjective measures. However, in our study, the performance of online students, relative to traditional students, was at least as high on the more objective measure (multiple-choice quizzes with the same format and containing the same questions in the online and traditional sections) as on the more subjective measure (final grade).

The anytime, anywhere nature of asynchronous online courses with today's technology may itself be a compensating factor. That is, while online courses may require greater student self-discipline, they also allow more flexibility for students to choose the times when they are productively engaged in the course rather than be constrained by the scheduled meeting time for the class. Also, at least some students themselves may appreciate the greater need to be disciplined in online courses, especially as online courses become common. Finally, instructors of online courses are usually aware of the fact that online students do not benefit from the structure and reminders that typically happen during in-class time in a traditional course. Thus, many online instructors can be expected to compensate by providing additional structure and reminders in, for example, the course syllabus, emails, and announcements.

This study has several limitations. First, the number of students in the online sections is relatively small. As a result, we cannot be sure that our finding that differences were statistically insignificant was because there actually are no real differences in the population of online and traditional students, or because of a lack of statistical power. Also, our results could be an artifact of the particular instructor who taught the course and/or the particular format or structure of the course. Thus, we cannot be sure of the generalizability of our results to other courses.

Another limitation is the lack of information about the student perceptions of online courses relative to traditional courses, perceptions of their own learning styles, and their reasons for choosing online versus traditional course structures. Such information, combined with measures of student performance, may help shed light on the degree to which there is variation across students in terms of the advantages or disadvantages of online courses relative to tradition courses. For example, our results are consistent with the notion that online and traditional courses are interchangeable and that it does not make any difference whether students take an online course or a traditional course. Our results are also consistent with a different reality. It could be that the courses are different. Some students, perhaps those with distance or scheduling issues and/or are well organized and can benefit from the anytime anywhere nature of online courses, will do better in an online course. Other students, perhaps those who value face-to-face interaction or who would benefit from more structure (e.g., scheduled classes), will do better in a traditional course. Then, students choose or are channeled into the course structure in which they are most productive. The good news is that these limitations can be overcome, or at least mitigated, by further research. In particular, we suggest that 
future research incorporate information on the reasons that students prefer online or traditional structures, and characteristics such as learning styles and self-discipline that may have a differential impact on student success in online versus traditional courses. Such research may help college advisors to better place students in courses where they are best able to learn and be successful. This line of research may also help a college or department better assess its current mix of traditional versus on-line course delivery, relative to the overall mission of the college/department.

\section{Conclusion}

There have been many studies comparing student outcomes between various forms of online and traditional courses. However, relatively few have focused on management courses, and even fewer have examined undergraduate management courses. Almost none have used as objective a measure of student performance as we are able to use in this study. Our results support and complement previous analyses finding that, when we control for factors such as class, major, and GPA, students in online courses do as well but not better than students in traditional courses. We also found that in the online sections, females performed at least as well as males. To the extent that women were once at a disadvantage in online courses, it appears that they are not any more. Our finding that students in online and traditional sections perform equally well would seem to be inconsistent with the persistent perception by some that online students are at a disadvantage because they need greater discipline in online courses. We discussed possible compensating mechanisms that are available in online courses and are utilized by students and faculty.

\section{References}

Alavi, M. (1994). Computer-mediated communication in the university classroom: an experiment on time discussions. MIS Quarterly, 18(2): 159-174.

Alavi, M., Yoo, Y. \& Vogel, D. (1997). Using technology to add value to management education. Academy of Management Journal, 40, 1310-1333.

Allen, I.E. \& Seaman, J. (2006). Making the Grade: Online Education in the United States, 2006. Needham, MA: The Sloan Consortium.

Arbaugh, J.B. (2005a). How much does "subject matter" matter? A study of disciplinary effects in online MBA courses. Academy of Management Learning \& Education, 4, 57-73.

Arbaugh, J.B. (2005b). Is there an optimal design for online MBA courses? Academy of Management Learning \& Education, 4, 135-149.

Arbaugh, J.B. \& Benbunan-Fich, R. (2006). An investigation of epistemological and social dimensions of teaching in online learning environments. Academy of Management Learning \& Education, 5, 435-447. 
Arbaugh, J.B. \& Stelzer, L. (2003). Learning and teaching via the web: what do we know?. In C. Wankel \& R. DeFillippi (eds.) Educating Managers with Tomorrow's Technologies (pp. 17-51). Greenwich, CT: Information Age Publishing.

Barrett, E. \& Lally, V. (1999). Gender differences in an online learning environment. Journal of Computer Assisted Learning, 15, 48-60.

Bocchi, J., Eastman, J.K., \& Swift, C.O. (2004, March/April). Retaining the online learner: profile of students in an online MBA program and implications for teaching them. Journal of Education for Business, 245-253.

Brower, H.H. (2003). On emulating classroom discussion in a distance-delivered OBHR course: creating an online learning community. Academy of Management Learning \& Education, 2, 22-36.

Brudenell, I. \& Carpenter, C.S. (1990). Adult learning styles and attitudes toward computer assisted instruction. Journal of Nursing Education, 29, 79-83.

Carlson, S. (2005, October 7). The net generation goes to college. The Chronicle of Higher Education, 52, A34.

Dash, E. (200, Oct 2). The virtual MBA: a work in progress. Business Week, 96.

Davis, M. \& Ralph, S. (2001). Stalling the learning process: group dynamics in cyberspace. Studies in the Education of Adults, 33(2), 217-229.

Dutton, J., Dutton, M. \& Perry, J. (2002). How do online students differ from lecture students? Journal of Asynchronous Learning Networks, 6(1). Retrieved at www.sloan-c.org/publications/jaln/v6n1/v6n1 dutton.asp.

Fjermestad, J., Hiltz, S.R. \& Zhang, Y. (2005). Effectiveness for students: comparisons of "in-seat" and ALN courses. In S.R. Hiltz \& R. Goldman (Eds.) Learning Together Online: Research on Asynchronous Learning Networks (pp. 39-80). Mahwah, NJ: Lawrence Erlbaum Associates.

Friday, E., Friday-Stroud, S.S, Green, A.L., \& Hill, A.Y. (2006) . A multi-semester comparison of student performance between multiple traditional and online sections of two management courses. Journal of Behavioral and Applied Management, 8, 66-81.

Goldman, R. \& Hiltz, S.R. (2005). Asynchronous learning networks: looking back and looking forward. In S.R. Hiltz \& R. Goldman (Eds.) Learning Together Online: Research on Asynchronous Learning Networks (pp. 261-280). Mahwah, NJ: Lawrence Erlbaum Associates. 
Hara, N. \& Kling, R. (2000). Student distress in a web-based distance education course. Information Communication and Society, 3, 557-579.

Hiltz, S.R \& Shea, P. (2005). The student in the online classroom. In S.R. Hiltz \& R. Goldman (Eds.) Learning Together Online: Research on Asynchronous Learning Networks (pp. 145-168). Mahwah, NJ: Lawrence Erlbaum Associates.

Hongmei, L. (2002). Distance education: pros, cons, and the future. Paper presented at the Annual Meetings of the Western States Communications Association, Long Beach, CA

Kamin, C., Glicken, A., Hall, M., Quarantillo, B. \& Merenstein, G. (2001). Evaluation of electronic discussion groups as a teaching/learning strategy in an evidencebased medicine course: a pilot study. Education for Health: Change in Learning and Practice, 14, 21-32.

Lemak, D. J., Shin, S.J., Reed, R. \& Montgomery, J.C. (2005). Academy of Management Learning \& Education, 4, 150-159.

Lohnes, S. \& Kinzer, C. (2007). Questioning assumptions about students' expectations for technology in college classrooms. Innovate: Journal of Online Education, 3(5) http://www.innovateonline.info/index.php?view=article\&id=431 (accessed June 2, 2007).

Madden, M.E. (2003). Planning for distance learning: issues and strategies. Journal of Behavioral and Applied Management, 4, 254-281.

McEwen, B.C. (2001). Web-assisted and online learning. Business Communication Quarterly, 64( 2), 98-103.

Moskal, P.D. \& Dziuban, C.D. (2001). Present and future directions for assessing cybereducation: the changing research paradigm. In L.R. Vandervert, L.V. Shavinina, \& R.A. Cornell (Eds.) Cybereducation: the future of long-distance learning (pp. 157-184). New York: Mary Ann Liebert.

Ocker, R.J. \& Yaverman, G.J. (1999). Asynchronous computer-mediated communication versus face-to-face collaboration: results on student learning, quality and satisfaction. Group Decision and Negotiation, 8, 427-440.

Proserpio, L. \& Gioia, D.A. (2007). Teaching in the virtual generation. Academy of Management Learning \& Education, 6, 69-80.

Shea, P, Swan, K., Fredericksen, E., \& Pickett, A. (2002). Student satisfaction and reported learning in the SUNY learning network. In J. Bourne \& J.C. Moore, (Eds.) Quality Online Education, 3, 145-155. Needham, MA: Sloan Center for Online Education. 
Smith, L.J. (2001). Content and delivery: a comparison and contrast of electronic and traditional MBA marketing planning courses. Journal of Marketing Education, 23, $35-44$. 